\title{
Clinico Radiological Profile of Pulmonary Thromboembolism in a Tertiary Care Hospital
}

\author{
Javid Abdullah .J $\mathbf{J}^{1}$, Subramanian .S ${ }^{2}$, Meenakshi . $\mathbf{N}^{3}$, Aruna Shanmuganathan ${ }^{4}$, Abubacker Sulaiman .F ${ }^{5}$ \\ ${ }^{1}$ Post Graduate Student, Department of Pulmonary Medicine, Chettinad Hospital and Research Institute, Chennai, India \\ ${ }^{2}$ Associate Professor, Department of Pulmonary Medicine, Chettinad Hospital and Research Institute, Chennai, India \\ ${ }^{3}$ Head and Professor, Department of Pulmonary Medicine, Chettinad Hospital and Research Institute, Chennai, India \\ ${ }^{4}$ Professor, Department of Pulmonary Medicine, Chettinad Hospital and Research Institute, Chennai, India \\ ${ }^{5}$ Associate Professor, Department of Radiology, Chettinad Hospital and Research Institute, Chennai, India
}

\begin{abstract}
Introduction: The diagnosis of Pulmonary embolism (PE) is often missed due its varied clinico-radiological presentation. The presentation may vary from an incidental finding in an asymptomatic patient to sudden death. High index of suspicion is required for early diagnosis and prevention of mortality since pulmonary embolism is Aim: To study the clinical and radiological profile of patients diagnosed with pulmonary thromboembolism. Methods: This Retrospective observational study was carried out in 30 patients diagnosed with pulmonary embolism admitted in the year 2012 to 2015 a tertiary care hospital and their clinical and radiological profile was recorded and analyzed. Results: The mean age of patients was 47.94 years. Male sex predominance was found. The most common predisposing factor was immobilization. Dyspnea was the most common symptom followed by swelling and pain of lower limb. Sinus tachycardia followed by $R V$ strain was the significant ECG finding. Pulmonary arterial hypertension as assessed by ECHO was present in $86 \%$ of patients. CT pulmonary angiogram finding revealed thrombus lodgment mainly in sub segmental level followed by segmental level. Conclusion: Pulmonary embolism must be suspected in those patients presenting with acute breathlessness with normal chest $X$ ray and sinus tachycardia particularly when associated with $R V$ strain pattern in the presence of risk factors for PE. The awareness that classical findings of PE in X-ray and ECG are uncommon, need to be stressed among general practitioners and physicians.
\end{abstract}

Keywords: Pulmonary thromboembolism, immobilization, normal chest x ray, pulmonary hypertension

\section{Introduction}

Pulmonary thromboembolism (PE) is a devastating clinical problem. Mortality rate of diagnosed and treated pulmonary embolism ranges from 3 to $8 \%$, but increases to about $30 \%$ in untreated pulmonary embolism [1]. Many cases are missed due to lack of clinical suspicion even in tertiary care centers. This is because of the fact that the clinical signs and symptoms of pulmonary thromboembolism are often found to be nonspecific. The availability of CT pulmonary angiography(CTPA) enables rapid diagnosis and hence management of $\mathrm{PE}$ in the appropriate clinical setting. Awareness of the varied clinic radiological presentation of pulmonary thromboembolism enables early diagnosis and reduction in mortality.

\section{Aims and Objectives}

To study the clinico-radiological profile of patients diagnosed with pulmonary thromboembolism.

\section{Methodology}

This Retrospective study was conducted at Department of Respiratory Medicine, Chettinad Hospital and Research Institute. Case Records of the patients with confirmed diagnosis of pulmonary thromboembolism admitted during the period of 2012- 2015 in this hospital were included in the study. Clinical history including risk factors, Radiology (Chest X ray \& CTPA) findings, Electrocardiography and
Echocardiographic findings were recorded from the case records. All the above parameters are recorded and analyzed.

\section{Results}

Thirty patients were included in this study and the results obtained after applying appropriate statistical tests are presented below.

\subsection{Demographic Characteristics}

The mean age of the patients was $47.94 \mathrm{yrs} \pm 16.38(95 \% \mathrm{CI}$ 41.93 to 53.94$) .66 \%$ of patients were males while $33 \%$ of patients were females. Thus male predominance in the ratio of 2:1 was noted.

\subsection{Predisposing factors}

The most common predisposing factor noted was prolonged immobilisation. $63.3 \%$ of patients had a history of prolonged immobilisation followed by trauma, nephrotic syndrome, protein $\mathrm{C}$ and $\mathrm{S}$ deficiency, atrial myxoma and oral contraceptive pills. Table 1

Table1: Predisposing factors

\begin{tabular}{|c|c|}
\hline Predisposing Factors & Number of Patients $(\mathrm{N}=30)$ \\
\hline Immobilization & $19(63.33 \%)$ \\
\hline Trauma & $5(16.66 \%)$ \\
\hline Nephrotic syndrome & $2(6.66 \%)$ \\
\hline Protein C and S deficiency & $2(6.66 \%)$ \\
\hline Atrial myxoma & $1(3.0 \%)$ \\
\hline Oral contraceptive pills & $1(3.0 \%)$ \\
\hline
\end{tabular}




\section{International Journal of Science and Research (IJSR) \\ ISSN (Online): 2319-7064}

Index Copernicus Value (2013): 6.14 | Impact Factor (2014): 5.611

\subsection{Clinical Features}

The most common symptom of presentation was dyspnea that was found in $84 \%$ cases followed by lower limb pain and swelling 53\%. Other presenting symptoms and their frequency is shown in Table-2.

\subsection{ECG and Echocardiogrphy}

The most common ECG finding noted was sinus tachycardia $(86 \%)$ followed by RV stain pattern $(70 \%)$. The Classical ECG finding ofS1Q3T3 pattern was present only in $20 \%$ of patients as shown in Table-3.Echocardiographic examination revealed the presence of pulmonary hypertension in twenty six patients $(86.6 \%)$ out of which sixteen $(62 \%)$ patients had a moderate PAH, six (23\%) patients had mild PAH and four $(15 \%)$ patients were found to have severe PAH.Table-4

\subsection{Radiologic Findings}

Normal chest radiograph was the most common X-ray finding $(66 \%)$, followed by Pleural effusion $(16.6 \%)$ and elevated right Hemidiaphragm(10\%) Table-5. The most common site of thrombus was found at sub segmental level followed by segmental and central part of main pulmonary artery on CTPA. Table 6

Table 2: Clinical presentation:

\begin{tabular}{|c|c|}
\hline Symptom & Number of Patients $(N=30)$ \\
\hline Dyspnea & $25(84 \%)$ \\
\hline Lower Limb pain \& swelling & $16(53 \%)$ \\
\hline Chest pain & $5(16 \%)$ \\
\hline Cough & $3(9 \%)$ \\
\hline Fever & $2(4 \%)$ \\
\hline Hemoptysis & $1(3 \%)$ \\
\hline
\end{tabular}

Table 3: ECG Findings:

\begin{tabular}{|c|c|}
\hline ECG Finding & Number of Patients $(N=30)$ \\
\hline Sinus Tachycardia & $26(86 \%)$ \\
\hline RV strain & $21(70 \%)$ \\
\hline S1Q3T3 Pattern & $6(20 \%)$ \\
\hline RBBB & $3(10 \%)$ \\
\hline
\end{tabular}

Table 4: ECHO findings

\begin{tabular}{|c|c|}
\hline$E C H O-P A P$ & Number of Patients $(N=30)$ \\
\hline Normal PAP & $4(15 \%)$ \\
\hline Mild PAH $(30-50 \mathrm{mmHg})$ & $6(23 \%)$ \\
\hline Moderate PAH $(50-70 \mathrm{mmHg})$ & $16(62 \%)$ \\
\hline Severe PAH $(>70 \mathrm{mmHg})$ & $4(15 \%)$ \\
\hline
\end{tabular}

Table 5: X-ray findings

\begin{tabular}{|c|c|}
\hline Chest X Ray & Number of Patients $(\mathrm{N}=30)$ \\
\hline Normal & $20(66 \%)$ \\
\hline Pleural Effusion & $5(16.6 \%)$ \\
\hline Elevated right Hemidiaphragm & $3(10 \%)$ \\
\hline
\end{tabular}

Table 6: CT Pulmonary Angiography Findings \begin{tabular}{l|l} 
Location of Thrombus & Number of Patients $(\mathrm{N}=30)$ \\
\hline
\end{tabular}

\begin{tabular}{|c|c|}
\hline Location of Thrombus & Number of Patients $(\mathrm{N}=30)$ \\
\hline Central & $4(13 \%)$ \\
\hline Segmental & $11(37 \%)$ \\
\hline Sub segmental & $15(50 \%)$ \\
\hline
\end{tabular}

\section{Discussion}

Pulmonary embolism presents with a wide clinical spectrum, from asymptomatic disease to life threatening massive embolism. The clinical presentation and most of the investigations done for the diagnosis of pulmonary embolism lacks specificity.

\subsection{Clinical Presentation}

B Taylor et al[4] in their study included 144 patients and observed that the common presenting symptom of pulmonary embolism is dyspnea followed by pleuritic chest pain and cough. Calwin David Singh et al[5] in their study included 35 patients and found that the common presenting symptom were dyspnea followed by syncope, chest pain, fever and cough. In our study, the common symptom was dyspnea followed by lower limb pain with swelling, chest pain, cough and fever.

\subsection{Epidemiologic characteristics and Risk factors:}

Calwin David Singh et al[5], in their study conducted in 35 patients who were diagnosed with pulmonary thromboembolism are under the mean age group of 52.1 years, with most common predisposing factors of immobilization followed by malignancy, protein $\mathrm{C}$ and $\mathrm{S}$ deficiency and HIV. Consuelo Huerta et al[6], in their study conducted in 633 patients who were diagnosed to have pulmonary thromboembolism. The mean age of patients was 63 and found the common risk factors are trauma (33\%), recent hip surgery and cancer. Also, he found that female patients have high risk factor due to their hormonal therapy. In our study immobilsation and trauma are the two most common risk factors.

\subsection{ECG and Echocardiographic findings:}

Sreeram et al [7] found among 85 of his patients, most common ECG finding was sinus tachycardia. Geibel et al [8] found that most common ECG findings was sinus tachycardia followed by atrial arrhythmia and right bundle branch block among 508 patients. Stein et al[9] and Keith et al[10] found S1Q3T3 pattern a pathognomic of PTE in ECG in $50 \%$ and $30 \%$ of their patients respectively. The most common ECG finding in our study was sinus tachycardia, followed by RV strain pattern, right bundle branch block .However in our study the classical pattern of S1Q3T3 pattern was found only in six patients.

Calwin David Singh et al[5]found 30 patients had pulmonary arterial hypertension among 31 patients with pulmonary thromboembolism. V Fuster et al [11] among, found among, 37 patients had thromboembolic pulmonary arterial hypertension out of 120 patients in echocardiography. In our study pulmonary arterial hypertension were found in most of the patients. Though the above studies of Calwin and Fuster documented presence of PAH in pulmonary embolism the severity was not evaluated. In our study ECHO was used to detect PAH and also to grade severity of PAH in PE. 


\section{International Journal of Science and Research (IJSR) \\ ISSN (Online): 2319-7064}

Index Copernicus Value (2013): 6.14 | Impact Factor (2014): 5.611

\subsection{Radiologic Findings}

Worsley et al [6] found that $12 \%$ of patients with PE had a normal chest $\mathrm{x}$ ray among 45 patients. Calwin Davidsingh et al [5] in their study among 35 patients found that 30 patients had normal chest $x$ ray. A. Toribicki et al[12] found that plate like atelectasis was the most common finding in chest $\mathrm{x}$ ray in $66 \%$, followed by pleural effusion and elevation of hemi diaphragm, among 64 patients diagnosed with pulmonary thromboembolism.

The value of CTPA in the diagnosis of PE was evaluated in several studies. M RemyJardin et al[13] found that among 112 patients diagnosed with pulmonary embolism, the most common finding was thrombus in sub segmental level followed by segmental and main pulmonary artery. Oser RF et al[14] found that emboli is located exclusively in sub segmental arterial branch among 79 patients. In our study the most common abnormality on CTPA was thrombus at the sub-segmental level. Saddle embolus was found in three patients overall.

\section{Conclusion}

Pulmonary embolism must be suspected in those patients presenting with acute breathlessness with normal chest X-ray and sinus tachycardia particularly when associated with RVstrain pattern in the presence of risk factors for PE. The awareness that classical findings of PE in X-ray and ECG are uncommon, need to be stressed among general practitioners and physicians, to enable early diagnosis and prevent mortality.

\section{References}

[1] KearonC. Natura 1 history of venous thromboembolism.Circulation. 2003;107:-2230.

[2] Ánderson Wheeler Venous thromboembolism. Risk factors and prophylaxis. Clin Chest Med.1995;16:235251.

[3] Gupta P Cancer Related Thrombophilia : Clinical Importanceand Management Strategies http://www.japi.org/october2005/R-877.

[4] B TaylorClinical presentation, evaluation, and diagnosis of the adult with suspected acute pulmonary embolism CHEST 2010;137:1382

[5] S.Calwin singh study of clinical profile and management of patients with pulmonary embolism - single center study indian heart j. 2014 mar; 66(2): 197-202.

[6] Worsley Chest Radiographic Findings In Patients With Acute Pulmonary Embolism: Observations From The Pioped Study Radiology 1993 Oct;189(1):133-6.

[7] Sreeram N, et al. Value of the 12 lead electrocardiogram at hospital admission in the diagnosis of pulmonary embolism. Am J Cardiol.1994;73:298. [PubMed]

[8] A. Geibel Prognostic value of the ECG on admission in patients with acute major pulmonary embolism EurRespir J 2005; 25: 843-848.

[9] Stein PD, Athanasoulis C, AlaviA et al. Complications and validity of pulmonary angiography in acute pulmonary embolism. Circulation1992; 85: 462-8.
[10]Keith v, Continuing risk of thromboembolism among patients with normal pulmonary angiograms. Chest 1995; 107: 1375-8.

[11]Fuster V, Steele PM, Edwards WD, et al. Primary pulmonary hypertension: Natural history and the importance of thrombosis. Circulation. 1984;70:580-7. [PubMed].

[12] Torbickietal.Guidelines on the diagnosis and management of pulmonary embolism: the task force for the diagnosis and management of Acute pulmonary embolism Eur Heart J 2008; 29:2276-2315.

[13] Remy-Jardin M, Tillie-Leblond I, Szapiro D, et al. CT angiography of pulmonary embolism in patients with underlying respiratory disease: impact of multislice CT on image quality and negative predictive value. EurRadiol 2002:12:1971-1978.

[14] Oser RF, Zuckerman DA, Gutierrez FR, Brink JA. Anatomic distribution of pulmonary emboli at pulmonary angiography: implications for cross-sectional imaging. Radiology 1996; 199: 31-5

\section{Author Profile}

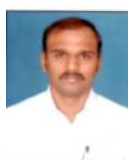

Dr. Jaffarullah Javidabdullah completed his MBBS from Kursk State Medical University Russia. At present he is pursuing his post graduate in respiratory medicine from chettinad hospital and research institute Chennai. 